\title{
Long-term outdoor air pollution and DNA methylation in circulating monocytes: results from the Multi-Ethnic Study of Atherosclerosis (MESA)
}

Gloria C. Chi" ${ }^{*}$, Yongmei Liu², James W. MacDonald ${ }^{3}$, R. Graham Barr ${ }^{4,5}$, Kathleen M. Donohue 4,5 , Mark D. Hensley ${ }^{1}$, Lifang Hou' ${ }^{6}$, Charles E. McCall', Lindsay M. Reynolds², David S. Siscovick ${ }^{8}$ and Joel D. Kaufman ${ }^{1,3}$

\begin{abstract}
Background: DNA methylation may mediate effects of air pollution on cardiovascular disease. The association between long-term air pollution exposure and DNA methylation in monocytes, which are central to atherosclerosis, has not been studied. We investigated the association between long-term ambient air pollution exposure and DNA methylation (candidate sites and global) in monocytes of adults (aged $\geq 55$ ).

Methods: One-year average ambient fine particulate matter $\left(\mathrm{PM}_{2.5}\right)$ and oxides of nitrogen $\left(\mathrm{NO}_{\mathrm{x}}\right)$ concentrations were predicted at participants' $(n=1,207)$ addresses using spatiotemporal models. We assessed DNA methylation in circulating monocytes at 1) 2,713 CpG sites associated with mRNA expression of nearby genes and 2) probes mapping to Alu and LINE-1 repetitive elements (surrogates for global DNA methylation) using Illumina's Infinium HumanMethylation450 BeadChip. We used linear regression models adjusted for demographics, smoking, physical activity, socioeconomic status, methyl-nutrients, and technical variables. For significant air pollution-associated methylation sites, we also assessed the association between expression of gene transcripts previously associated with these CpG sites and air pollution.
\end{abstract}

Results: At a false discovery rate of 0.05, five candidate CpGs (cg20455854, cg07855639, cg07598385, cg17360854, and cg23599683) had methylation significantly associated with $\mathrm{PM}_{2.5}$ and none were associated with NOx. Cg20455854 had the smallest $p$-value for the association with $\mathrm{PM}_{2.5}\left(p=2.77 \times 10^{-5}\right)$. mRNA expression profiles of genes near three of the $\mathrm{PM}_{2.5}$-associated CpGs (ANKHD1, LGALS2, and ANKRD11) were also significantly associated with $\mathrm{PM}_{2.5}$ exposure. Alu and LINE-1 methylation were not associated with long-term air pollution exposure.

Conclusions: We observed novel associations between long-term ambient air pollution exposure and sitespecific DNA methylation, but not global DNA methylation, in purified monocytes of a multi-ethnic adult population. Epigenetic markers may provide insights into mechanisms underlying environmental factors in complex diseases like atherosclerosis.

Keywords: Air pollution, $\mathrm{PM}_{2.5}, \mathrm{NO}_{x}$, ANKHD1, LGALS2, ANKRD11, BAZ2B, PPIE, DNA methylation

\footnotetext{
*Correspondence: glochi@uw.edu

${ }^{1}$ Department of Epidemiology, School of Public Health, University of

Washington, 1959 NE Pacific St, Box 357236, Seattle, WA 98195, USA

Full list of author information is available at the end of the article
} 


\section{Background}

Ambient air pollution contributed to over 3.2 million premature deaths and over 76 million years of healthy life lost globally in 2010 and ranked in the top ten leading risk factors for global mortality and disease [1]. Exposure to fine particulate matter $\left(\mathrm{PM}_{2.5}\right)$ has been associated with a variety of conditions including cardiopulmonary disease, diabetes, premature birth, low birthweight, cancer, and cognitive changes [2].

Many prior studies focused on the effect of air pollution exposure on the risk of cardiovascular mortality and morbidity. Landmark studies including the Harvard Six Cities and the American Cancer Society studies demonstrated associations between $\mathrm{PM}_{2.5}$ exposure and allcause and cardiovascular mortality in the United States [3-8]. In addition to mortality, air pollution has also been associated with ischemic heart disease, stroke, and progression of atherosclerosis [3, 6, 9-12]. Associations between air pollution and cardiovascular disease have also been identified in other countries, including Europe and China. Long-term exposure to particulate matter was associated with acute coronary events in 11 European cohorts as part of the ESCAPE Project [13], and particulate matter and nitrogen dioxide were associated with increased risk of cardiovascular and cerebrovascular disease $[14,15]$. In a recent review and meta-analysis, a $10 \mu \mathrm{g} / \mathrm{m}^{3}$ higher $\mathrm{PM}_{2.5}$ exposure was associated with a $6 \%$ (95\% confidence interval [CI]: 4\%, 8\%) higher risk for all-cause and 11\% (95\% CI: 5\%, 16\%) higher risk for cardiovascular mortality [16]. Although much uncertainty exists regarding underlying biological mechanisms for this association, DNA methylation has been postulated to mediate the effects of air pollution on cardiovascular disease (CVD) [17].

DNA methylation is a chemical modification of DNA that involves the addition of a methyl group to cytosine and predominantly occurs at cytosine-guanine dinucleotide (CpG) sites [18]. DNA methylation in CpG-rich promoters tends to repress transcription whereas the effect is context-dependent in other genomic regions.

Previous studies show that DNA methylation patterns are associated with atherosclerosis [19], ischemic heart disease [20], and blood pressure while others have suggested DNA methylation as a biomarker for cardiovascular disease [21]. Moreover, exposure to air pollutants such as black carbon, particulate matter, benzene, and $\mathrm{SO}_{4}$ led to a genome-wide reduction in DNA methylation, or global hypomethylation, and were associated with methylation levels of candidate genes [22-26].

Results from past studies, however, are difficult to interpret due to several limitations. First, they were limited by the use of peripheral blood leukocytes, which are composed of a mixture of cells that have unique DNA methylation profiles. Since DNA methylation is cell- specific, it is more relevant to study purified samples of a single cell type such as monocytes. Monocytes play an important role in atherogenesis by promoting chronic inflammation and differentiating into macrophages that accumulate in plaques [27]. In addition, most prior studies did not measure gene expression to investigate the potential biological relevance of methylation differences. Some studies were further limited by potential exposure misclassification and measurement error in air pollution exposures.

We evaluated the association between long-term exposure to ambient air pollution and global and candidate CpG site DNA methylation in circulating monocytes of 1,207 participants from the Multi-Ethnic Study of Atherosclerosis (MESA). Candidate CpG sites were those with methylation previously associated with expression of nearby genes in the MESA cohort. For significant air pollution-associated methylation sites, we also assessed the association between expression of genes previously associated with the methylation sites and air pollution. MESA uniquely couples methylomic and transcriptomic data in monocytes with advanced air pollution exposure predictions.

\section{Methods \\ Study population}

MESA enrolled 6,814 participants aged 45-84 free of CVD at baseline from July 2000 to July 2002 at six field centers (Baltimore, MD; Chicago, Illinois; Los Angeles, CA; New York, NY; St. Paul, MN, and Winston-Salem, NC) with ongoing follow-up [28]. The MESA cohort is a diverse, population-based sample of $38 \%$ white, $28 \%$ black, 22\% Hispanic, and 12\% Asian participants, of whom half are women. Study participants underwent extensive physical exams to determine subclinical CVD and questionnaires to obtain information on sociodemographic, lifestyle, and psychosocial factors. MESA Air began in 2004 and builds on the original MESA study by adding new participants, outcome measurements, and air pollution exposure assessments of ambient fine particulate matter $\left(\mathrm{PM}_{2.5}\right)$, oxides of nitrogen $\left(\mathrm{NO}_{\mathrm{X}}\right)$, and black carbon [29]. The MESA Epigenomics and Transcriptomics Study obtained genome-wide methylomic and transcriptomic profiles of $\mathrm{CD} 14+$ purified monocytes from 1,264 randomly selected MESA participants from four MESA field centers (Baltimore, MD; New York, NY; St. Paul, MN; and Winston-Salem, NC) at the 5th examination (April 2010-February 2012) [30]. The study protocol was approved by the Institutional Review Boards at Johns Hopkins Medical Institutions, University of Minnesota, Columbia University Medical Center, Wake Forest University Health Sciences, and University of Washington. All participants signed informed consent. 
This study was restricted to participants who had available methylomic, transcriptomic, and air pollution data $(n=1,207)$. Since DNA methylation and gene expression data were not available for participants from the Los Angeles and Chicago MESA sites, there were no Asian participants in our analytic sample. Those included in the study were generally representative of all participants from the 5th examination at the four MESA field centers represented except for having fewer black participants, more Hispanic participants, and fewer participants from Winston-Salem, NC (see Additional file 1: Table S1).

\section{Air pollution assessment}

$\mathrm{PM}_{2.5}$ and $\mathrm{NO}_{\mathrm{X}}$ predictions are available through MESA Air as likelihood-based 2-week averages for all participants from 1999 to 2012. The air pollution prediction method has been described previously [31, 32]. Sources of monitoring data included the U.S. Environmental Protection Agency-operated Air Quality System monitors, including data from the Interagency Monitoring of Protected Visual Environments (IMPROVE) network, and cohort-specific monitoring. Additional data from the New York City Community Air Survey (NYCCAS) were used in New York City [32, 33]. In each study region, spatiotemporal models that accommodated unbalanced monitoring data were developed to predict ambient air pollution concentrations. The prediction model included monitoring data and over 300 geographic variables, such as distance to nearest road, population density, land use, and dispersion model outputs [31, 32]. Partial least squares was used to reduce the dimensionality of geographic covariates for inclusion in the models. Spatial smoothing was used to borrow strength between spatially close observations [32]. This modeling technique used the combined data to characterize seasonal and shorter-term time trends, key sources of spatial variability within the study communities, and underlying spatial and spatiotemporal correlation. For the present analyses, individual-level outdoor residential concentrations of $\mathrm{PM}_{2.5}$ and $\mathrm{NO}_{\mathrm{X}}$ were averaged over the 12 months prior to blood draw.

\section{DNA methylation and gene expression quantification}

Blood was drawn at the 5th examination (April 2010February 2012). Monocytes were purified on-site by trained technicians following standardized protocols with extensive quality control measures using antiCD14-coated magnetic beads and AutoMACs automated magnetic separation unit (Miltenyi Biotec, Bergisch Gladbach, Germany) [30]. DNA and RNA were extracted simultaneously from purified monocytes using AllPrep DNA/RNA Mini Kit (Qiagen, Inc., Hilden, Germany).
Genome-wide methylation profiles of over 485,000 CpG sites were characterized in purified monocytes using the Infinium HumanMethylation450 BeadChip (450k; Illumina, Inc. CA, USA). Bisulfite conversion of DNA fragments was performed with the EZ-96 DNA Methylation Kit (Zymo Research, Orange, CA, USA). Bead-level methylation data were summarized using the Illumina GenomeStudio software, and then raw methylation calls were normalized and converted to $\mathrm{M}$-values (log ratio of methylated to unmethylated intensities). The M-value was used in statistical analyses due to better statistical performance in differential methylation analyses [34]. The Illumina HumanHT-12 v4 Expression BeadChip and Ilumina Bead Array Reader were used to obtain genome-wide expression profiles of over 48,000 transcripts (Illumina, Inc. CA, USA) [30]. A random sampling technique was used to assign samples, including control samples, to chips and positions to mitigate batch effects for both arrays. Data pre-processing using Bioconductor [35] in R [36] and quality control methods were previously described [30], and more details can be found in the Additional file 1. All allosome CpGs were removed prior to analysis.

To reduce dimensions of our genome-wide methylation data, we focused on CpG sites more likely to be functionally relevant. Previous work in this cohort identified 11,203 methylation sites that were associated with the cis-expression of 3,093 gene transcripts in a sample of 1,264 randomly selected MESA participants [30]. There were 2,713 unique CpG sites among the most significant CpG sites associated with each of the 3,093 transcripts. We tested the association of these 2,713 expression-associated methylation sites (eMS) with $\mathrm{PM}_{2.5}$ and $\mathrm{NO}_{\mathrm{X}}$. In our study, eMS were annotated with respect to the gene with expression most significantly associated to the eMS. Additional nearest gene annotation for the top eMS can be found in the Additional file 1: Tables S2 and S3.

Alu and long interspersed nuclear elements (LINE)-1 repetitive element DNA methylation were used as surrogates for global DNA methylation. By intersecting probe locations from the Infinium 450k array with RepeatMasker [37], we identified 12,456 and 9,507 probes for Alu and LINE-1 repetitive elements, respectively, that passed quality control exclusion. Median Alu and LINE-1 DNA methylation were calculated for each participant for use in regression analyses.

\section{Statistical analysis}

The associations between air pollution $\left(\mathrm{PM}_{2.5}\right.$ or $\left.\mathrm{NO}_{\mathrm{X}}\right)$ and methylation $\mathrm{M}$-values at candidate $\mathrm{CpGs}$ were assessed with least squares regression and robust empirical Bayes moderated t-statistics using the limma package from Bioconductor [38]. To account for multiple 
testing of the 2,713 eMS, we controlled the false discovery rate (FDR) at 0.05 using the Benjamini and Hochberg method [39]. For eMS that were significantly associated with $\mathrm{PM}_{2.5}$ or $\mathrm{NO}_{\mathrm{X}}$, we also tested the association between the transcript paired to that $\mathrm{eMS}$ and $\mathrm{PM}_{2.5}$ or $\mathrm{NO}_{\mathrm{X}}$ using linear models with least squares regression and robust empirical Bayes moderated $\mathrm{t}$-statistics using limma. The associations between air pollution and median Alu and median LINE-1 methylation were examined using linear regression with robust standard errors.

In all analyses, we adjusted for age, sex, race/ethnicity (black, Hispanic, white), household income, education, neighborhood socioeconomic status, smoking (smoking status and pack-years), secondhand smoke, body mass index, recent infection, methyl nutrient intake (continuous folate, vitamin B12, vitamin B6, methionine, zinc), physical activity, study site, microarray chip, and chip position (DNA methylation analysis only). We also adjusted for residual sample contamination by non-monocytes by adjusting for enrichment scores for neutrophils, B cells, $\mathrm{T}$ cells, and natural killer cells.

No covariate had more than $4 \%$ missing data. Multivariate imputation using chained equations was used to impute missing values in Stata 13 [40]. Since the proportion of missing data was low, only one iteration was used in association analyses.

Sensitivity analyses were conducted to investigate whether the association between exposure to $\mathrm{PM}_{2.5}$ and $\mathrm{NO}_{\mathrm{X}}$ and Alu and LINE-1 methylation would be sensitive to a shorter averaging period of two weeks for the MESA Air likelihood-based air pollution predictions. In addition to including all covariates in the main study, this analysis also adjusted for temperature, relative humidity, month of blood draw, and day of week of blood draw. Additional sensitivity analyses were also conducted to assess potential effect modification by sex and race/ethnicity by fitting interaction terms with air pollution.

\section{Functional annotation analysis}

In silico functional prediction of chromatin states in monocytes was performed using ChromHMM [41] to predict segmentation among six states, based on histone modifications in monocyte samples from the BLUEPRINT [42, 43] (H3K27ac, H3K4me1, H3K4me3) and the Encyclopedia of DNA Elements (ENCODE) [44] (H3K36me3) projects. Annotation also included DNase hypersensitive hotspot data in a monocyte sample (Sample ID RO01746, data generated by the UW ENCODE group) and transcription factor binding sites detected in any cell type available from ENCODE [44]. Data was accessed from the UCSC Genome Browser [45] and the Gene Expression Omnibus (https://www.ncbi.nlm.nih.gov/geo/).

\section{Results}

The analytic sample consisted of 1,207 participants with mean age of 69.6 (Table 1). Of these participants, $21.2 \%$ were black, $31.6 \%$ were Hispanic, and $47.2 \%$ were white. Roughly half were female, and most were former (50.3\%) or never $(40.3 \%)$ smokers with average body mass index of $29.7 \mathrm{~kg} / \mathrm{m}^{2}$. Over $65 \%$ of participants received education beyond high school, and nearly $40 \%$ had income over $\$ 50,000$. Median Alu and median LINE-1 methylation were 2.4 and $2.6 \mathrm{M}$-value units, respectively. Figure 1 shows plots of site-specific 12-month average ambient $\mathrm{PM}_{2.5}$ and $\mathrm{NO}_{\mathrm{X}}$ predictions. The overall average $\mathrm{PM}_{2.5}$ and $\mathrm{NO}_{\mathrm{X}}$ predictions were $10.7 \mu \mathrm{g} / \mathrm{m}^{3}$ (interquartile range $[\mathrm{IQR}]=2.2 \mu \mathrm{g} / \mathrm{m}^{3}$ ) and $28.7 \mathrm{ppb}(\mathrm{IQR}=$ $31.9 \mathrm{ppb}$ ), respectively. $\mathrm{PM}_{2.5}$ and $\mathrm{NO}_{\mathrm{X}}$ were positively correlated (correlation coefficient $=0.82$ ). Figure 2 shows maps of $\mathrm{PM}_{2.5}$ and $\mathrm{NO}_{\mathrm{X}}$ predictions over the four study regions, along with participant locations shown in black dots that are jittered to protect confidentiality.

Figure 3 shows a plot of the $-\log _{10}$ (p-values) against genomic position from linear regression analysis of 2,713 eMS with $\mathrm{PM}_{2.5}$. We found five eMS had methylation significantly (FDR <0.05) associated with $\mathrm{PM}_{2.5}$ (four positively and one negatively), and they included cg20455854 (ANKHD1; ankyrin repeat and KH domain containing 1), $\operatorname{cg} 07855639$ (LGALS2; lectin, galactosidebinding, soluble, 2), cg07598385 (ANKRD11; ankyrin repeat domain 11), cg17360854 (BAZ2B; bromodomain adjacent to zinc finger domain, 2B), and cg17360854 (PPIE; peptidylprolyl isomerase E). The significant eMS associated with $\mathrm{PM}_{2.5}$ are shown in Table 2. The eMS cg20455854 has methylation associated with ANKHD1 expression and is the eMS with the smallest p-value for the association with $\mathrm{PM}_{2.5}$ (coefficient $=0.139$, 95\% CI: $0.074,0.203$; per $2.5 \mu \mathrm{g} / \mathrm{m}^{3} ; p=2.77 \times 10^{-5}$ ). Cg20455854 is located within a DNase hypersensitivity site (monocyte data from ENCODE), a transcription factor binding site (any cell type from UCSC Genome Browser), and a predicted strong enhancer region (see Additional file 1: Table S2). $\mathrm{NO}_{\mathrm{X}}$ exposure was not significantly associated with methylation of any eMS (see Additional file 1: Table S3).

Although all candidate $\mathrm{CpGs}$ had methylation previously associated with mRNA expression of a nearby gene in this cohort, not all of these mRNA expression profiles associated with $\mathrm{PM}_{2.5}$-associated eMS were significantly (FDR <0.05) differentially expressed with respect to air pollution. Three of the five genes with mRNA expression previously associated with the significant $\mathrm{PM}_{2.5}$-eMS had mRNA expression also associated with $\mathrm{PM}_{2.5} \cdot \mathrm{PM}_{2.5}$ exposure was negatively associated with ANKHD1 (coefficient $=-0.048 ; 95 \%$ CI: $-0.074,-0.022$; per $\left.2.5 \mu \mathrm{g} / \mathrm{m}^{3} ; p=3.71 \times 10^{-4}\right)$, LGASL2 $(\beta=-0.147 ; 95 \%$ CI: $-0.240,-0.053$; per $\left.2.5 \mu \mathrm{g} / \mathrm{m}^{3} ; p=0.002\right)$, and 
Table 1 Descriptive characteristics of 1,207 MESA participants

\begin{tabular}{|c|c|c|c|c|c|}
\hline & Total & New York & Maryland & Minnesota & North Carolina \\
\hline & $\begin{array}{l}\mathrm{n}(\%) \text { or } \\
\text { mean } \pm \mathrm{SD}\end{array}$ & $\begin{array}{l}\mathrm{n}(\%) \text { or } \\
\text { mean } \pm \mathrm{SD}\end{array}$ & $\begin{array}{l}\mathrm{n}(\%) \text { or } \\
\text { mean } \pm \mathrm{SD}\end{array}$ & $\begin{array}{l}\mathrm{n}(\%) \text { or } \\
\text { mean } \pm \mathrm{SD}\end{array}$ & $\begin{array}{l}\mathrm{n}(\%) \text { or } \\
\text { mean } \pm \mathrm{SD}\end{array}$ \\
\hline Age (y) & $69.6 \pm 9.4$ & $69.7 \pm 9.7$ & $70.7 \pm 9.0$ & $68.5 \pm 9.5$ & $71.1 \pm 7.0$ \\
\hline \multicolumn{6}{|l|}{ Race/ethnicity, \% } \\
\hline White & $570(47.2)$ & $82(20.6)$ & $173(57.5)$ & $267(58.4)$ & $48(94.1)$ \\
\hline Black & $256(21.2)$ & $125(31.4)$ & $128(42.5)$ & $0(0)$ & $3(5.9)$ \\
\hline Hispanic & 381 (31.6) & $191(48.0)$ & $0(0)$ & $190(41.6)$ & $0(0)$ \\
\hline \multicolumn{6}{|l|}{ Sex $\%$} \\
\hline Female & $623(51.6)$ & $231(58.0)$ & $156(51.8)$ & $208(45.5)$ & $28(54.9)$ \\
\hline Male & $584(48.4)$ & $167(42.0)$ & $145(48.2)$ & $249(54.5)$ & $23(45.1)$ \\
\hline \multicolumn{6}{|l|}{ Smoking status, $\%^{\mathrm{a}}$} \\
\hline Never & $484(40.3)$ & $181(45.8)$ & $120(40.1)$ & $165(36.3)$ & $18(35.3)$ \\
\hline Former & $604(50.3)$ & $184(46.6)$ & $149(49.8)$ & 244 (53.6) & $27(52.9)$ \\
\hline Current & $112(9.3)$ & $30(7.6)$ & $30(10.0)$ & $46(10.1)$ & $6(11.8)$ \\
\hline Secondhand smoke, (hours per week) ${ }^{a}$ & $3.7 \pm 20.5$ & $2.3 \pm(11.1)$ & $5.9 \pm 35.3$ & $3.3 \pm 12.3$ & $5.5 \pm 14.2$ \\
\hline Body mass index $\left(\mathrm{kg} / \mathrm{m}^{2}\right)^{\mathrm{a}}$ & $29.7 \pm 5.5$ & $29.3 \pm 5.6$ & $30.1 \pm 5.7$ & $29.8 \pm 5.3$ & $28.5 \pm 5.8$ \\
\hline Physical activity (MET-min/wk m-su) ${ }^{a}$ & $5,696.2 \pm 7,205.6$ & $5,364.6 \pm 7,139.0$ & $5,978.8 \pm 9,405.6$ & $5,942.0 \pm 5,770.6$ & $4,405.0 \pm 3,314.3$ \\
\hline \multicolumn{6}{|l|}{ Education, \% ${ }^{\mathrm{a}}$} \\
\hline Less than high school & $176(14.6)$ & $94(23.6)$ & $20(6.7)$ & $61(13.3)$ & $1(2.0)$ \\
\hline High school & $236(19.6)$ & $76(19.1)$ & $59(19.7)$ & $95(20.8)$ & $6(11.8)$ \\
\hline Some college but no degree & $212(17.6)$ & $68(17.1)$ & $59(19.7)$ & $75(16.4)$ & $10(19.6)$ \\
\hline Bachelor's/Associate/Technical & $373(31.0)$ & $99(24.9)$ & $81(27.1)$ & $171(37.4)$ & $22(43.1)$ \\
\hline Advanced degree & $208(17.3)$ & $61(15.3)$ & $80(26.8)$ & $55(12.0)$ & $12(23.5)$ \\
\hline \multicolumn{6}{|l|}{ Income, $\%^{a}$} \\
\hline$<\$ 25,000$ & $297(25.5)$ & $131(33.5)$ & $49(17.3)$ & $110(24.9)$ & $7(14.3)$ \\
\hline$\$ 25,000-\$ 49,999$ & $371(31.9)$ & $125(32.0)$ & $77(27.2)$ & $150(34.0)$ & $19(38.8)$ \\
\hline$\$ 50,000-\$ 99,999$ & $333(28.6)$ & $89(22.8)$ & $104(36.7)$ & $125(28.3)$ & $15(30.6)$ \\
\hline$\$ 100,000$ or more & $163(14.0)$ & $46(11.8)$ & $53(18.7)$ & $56(12.7)$ & $8(16.3)$ \\
\hline Neighborhood socioeconomic status factor score ${ }^{a}$ & $-0.41 \pm 1.09$ & $-1.06 \pm 1.42$ & $-0.27 \pm 0.85$ & $0.004 \pm 0.62$ & $-0.21 \pm 0.91$ \\
\hline \multicolumn{6}{|l|}{ Recent infection, $\%^{\mathrm{a}}$} \\
\hline No & $922(77.2)$ & $293(73.8)$ & $225(76.0)$ & $365(80.8)$ & $39(78.0)$ \\
\hline Yes & $273(22.8)$ & $104(26.2)$ & $71(24.0)$ & $87(19.2)$ & $11(22.0)$ \\
\hline Folate $(\mathrm{mcg})^{a}$ & $317.1 \pm 169.2$ & $308.5 \pm 162.7$ & $301.9 \pm 165.0$ & $333.6 \pm 175.6$ & $324.1 \pm 175.9$ \\
\hline Vitamin B12 (mcg) ${ }^{a}$ & $3.9 \pm 3.8$ & $4.1 \pm 5.1$ & $3.6 \pm 3.2$ & $4.0 \pm 2.8$ & $3.9 \pm 2.8$ \\
\hline Vitamin B6 (mg) ${ }^{a}$ & $1.5 \pm 0.8$ & $1.4 \pm 0.7$ & $1.5 \pm 0.9$ & $1.6 \pm 0.8$ & $1.5 \pm 0.7$ \\
\hline Methionine $(g)^{a}$ & $1.4 \pm 0.8$ & $1.3 \pm 0.8$ & $1.3 \pm 0.9$ & $1.5 \pm 0.8$ & $1.4 \pm 0.8$ \\
\hline Zinc $(m g)^{a}$ & $8.9 \pm 5.2$ & $8.4 \pm 4.9$ & $8.3 \pm 5.6$ & $9.6 \pm 5.2$ & $8.8 \pm 4.3$ \\
\hline
\end{tabular}

a Contains missing values

ANKRD11 expression $(\beta=-0.075 ; 95 \%$ CI: -0.142 , -0.008; per $2.5 \mu \mathrm{g} / \mathrm{m}^{3} ; p=0.028$ ) (Table 2).

Median DNA methylation of Alu was not associated with $\mathrm{PM}_{2.5}$ (coefficient $=-0.003 ; 95 \% \mathrm{CI}:-0.006,0.001$; $p=0.155$ ) or $\mathrm{NO}_{\mathrm{X}}$ (coefficient $=0.001 ; 95 \% \mathrm{CI}:-0.006$, $0.008 ; p=0.719$ ) after covariate adjustment (Table 3).
Median DNA methylation of LINE-1 was also not associated with $\mathrm{PM}_{2.5}$ (coefficient $=-0.003 ; 95 \% \mathrm{CI}:-0.007$, $0.001 ; p=0.177$ ) or $\mathrm{NO}_{\mathrm{X}}$ (coefficient $=-0.0004 ; 95 \% \mathrm{CI}$ : $-0.009,0.008 ; \quad p=0.927$ ) after covariate adjustment (Table 3). Results were not sensitive to using a 2-week averaging period for air pollutants (see Additional file 1: 

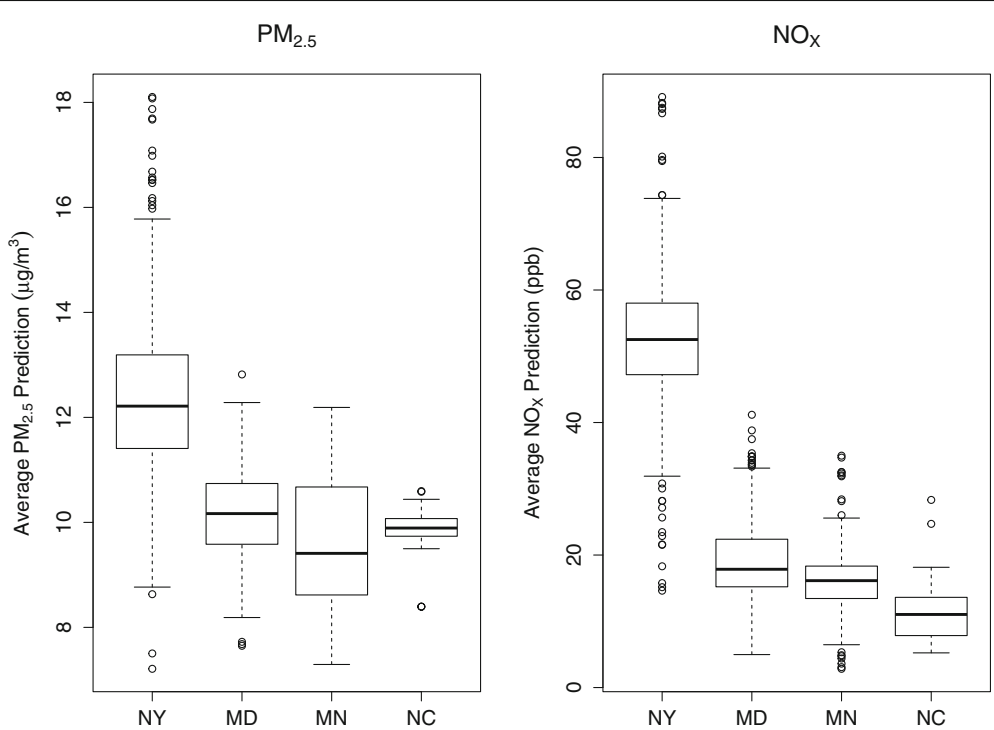

Fig. 1 Ambient predictions of $\mathrm{PM}_{2.5}$ and $\mathrm{NO}_{\mathrm{X}}$ by site, averaged over 12 months prior to blood draw. Site abbreviations: NY, New York; MD, Maryland; MN, Minnesota; NC, North Carolina. The lower and upper ends of the box represent the 25th and 75th percentiles, respectively, and the center bar represents the median. The bottom and top whiskers represent 1.5 times the interquartile distance above and below the 25th and 75th percentiles, respectively, and the circles indicate outliers

Table S4). We did not identify interactions between air pollution and sex or race/ethnicity (data not shown).

\section{Discussion}

We examined the associations between long-term air pollution exposure and DNA methylation in monocytes. We found air pollution to be significantly associated with site-specific DNA methylation, but not global DNA methylation. In order to identify potentially functionally relevant genes involved in the pathogenesis of air pollution-related cardiovascular disease, we focused on a set of CpG sites that were previously associated with expression of nearby genes. In monocytes, we detected five CpGs with methylation associated with long-term $\mathrm{PM}_{2.5}$ exposure, of which three were potentially functionally related to

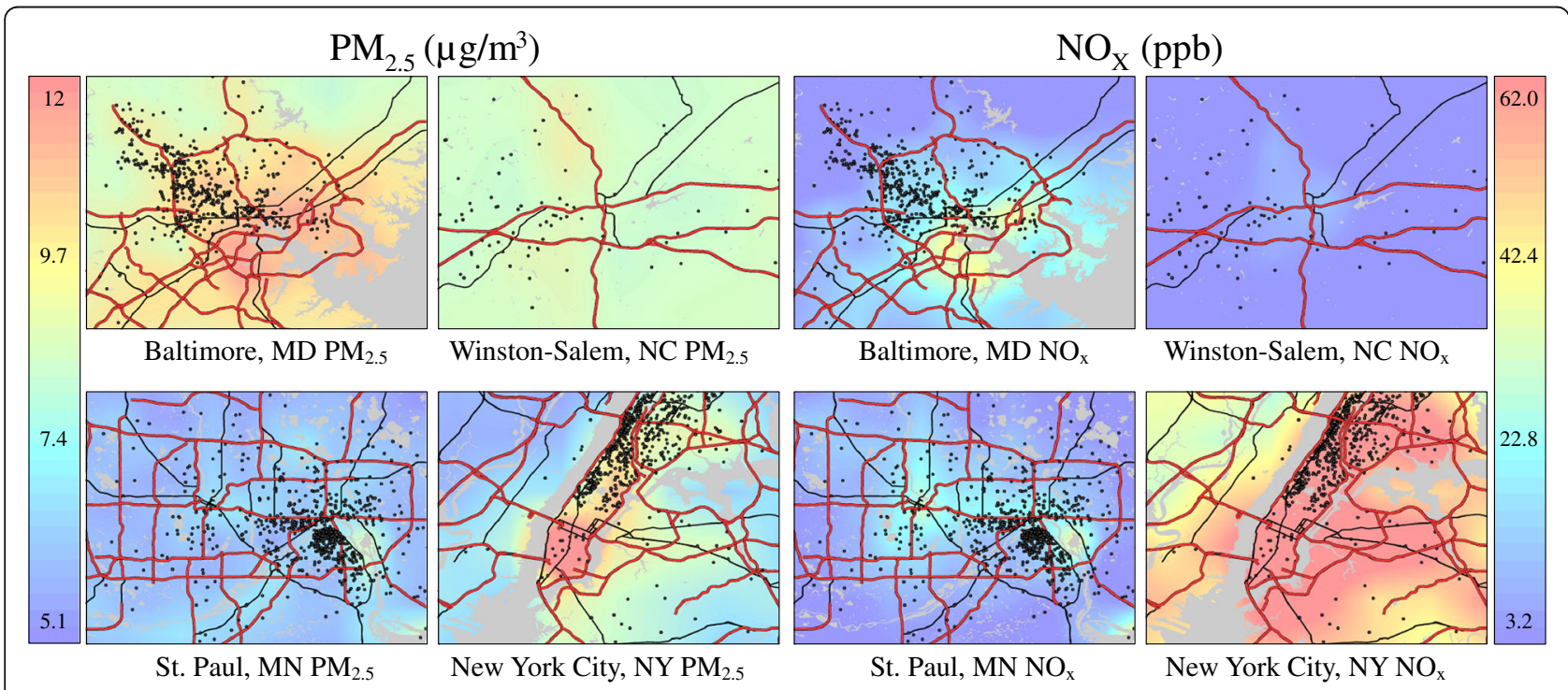

Fig. 2 Maps of estimated $\mathrm{PM}_{2.5}$ and NOx concentrations by MESA Air study site. The maps show smoothed air pollution predictions, which may reduce the visibility of fine-scale variation in concentrations. Black dots represent participant locations and are jittered to protect participant confidentiality 

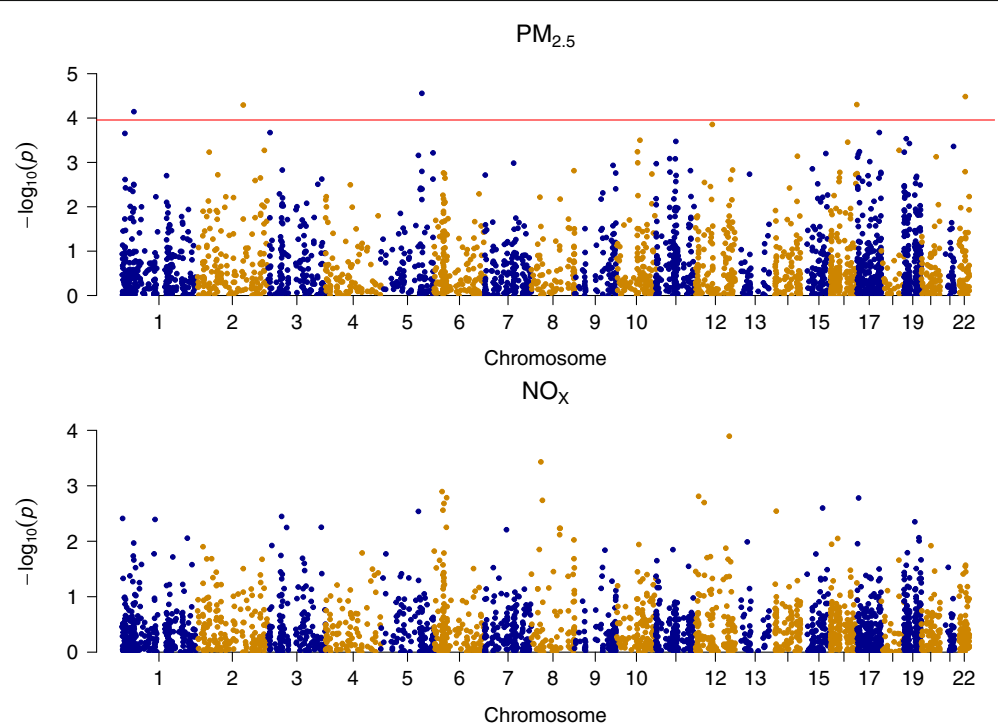

Fig. 3 Association between $\mathrm{PM}_{2.5}$ and $\mathrm{NO}_{x}$ and 2,713 expression-associated methylation sites. Red line demarcates statistical significance at a false discovery rate of $5 \%$. Plot for $\mathrm{NO}_{x}$ does not have a red line because no sites were statistically significant

genes with expression also correlated with air pollution. No site-specific methylation sites were associated with long-term $\mathrm{NO}_{\mathrm{X}}$ exposure.

Genes with both regulatory DNA methylation site(s) and mRNA expression that are associated with air pollution may be more plausibly involved in the pathogenesis of air pollution-related disease. In this study, we identified three such genes: ANKHD1, LGALS2, and ANKRD11. While we did not formally evaluate whether DNA methylation mediates the association of air pollution with atherosclerotic cardiovascular disease in this report and temporal relationships are not clear, the identification of these genes suggests that DNA methylation may potentially link air pollution inhalation with changes in monocyte gene expression which could contribute to disease.

ANKHD1 function in monocytes is unknown, but it is highly expressed in acute leukemia, multiple myeloma, and prostate cancer and may support proliferation and cell cycle progression of cancer cells [46-49]. ANKHD1 contains multiple ankyrin repeats [50], which mediate protein-protein interactions and have been found in proteins involved in various cellular functions including cellcell signaling, cytoskeleton integrity, cell cycle control, transcriptional regulation, and inflammatory response [51]. The role that ANKHD1 plays in air pollution-related disease is unclear, but the presence of ankyrin repeats suggests that ANKHD1 may play an important cellular function. This study is the first to demonstrate an association between an environmental pollutant and ANKHD1 DNA methylation and expression. In our study, $\mathrm{PM}_{2.5}$ exposure correlated with higher methylation of ANKHD1-eMS cg20455854 and lower mRNA expression of ANKHD1. The location of cg20455854 within a DNase hypersensitivity site, transcription factor binding site, and predicted strong enhancer region provides supports a potentially functional $\mathrm{PM}_{2.5}-\mathrm{eMS}$.

Table 2 eMS with $\mathrm{PM}_{2.5}$-associated methylation and association between corresponding transcript gene expression with $\mathrm{PM}_{2.5}$, ranked by gene expression association with $\mathrm{PM}_{2.5}$

\begin{tabular}{|c|c|c|c|c|c|c|c|c|c|}
\hline \multirow[b]{2}{*}{$G_{e n e}^{a}$} & \multirow[b]{2}{*}{ Chr } & \multicolumn{4}{|c|}{ DNA Methylation } & \multicolumn{4}{|l|}{ Gene Expression } \\
\hline & & CpG & $\beta(95 \% \mathrm{Cl})$ & $P$-value & $\begin{array}{l}\text { Adjusted } \\
P \text {-value }\end{array}$ & Illumina Transcript & $\beta(95 \% \mathrm{Cl})$ & $P$-value & $\begin{array}{l}\text { Adjusted } \\
P \text {-value }\end{array}$ \\
\hline \multicolumn{10}{|l|}{$\mathrm{PM}_{2.5}$} \\
\hline ANKHD1 & 5 & cg20455854 & $0.139(0.074,0.203)$ & $2.77 \times 10^{-5}$ & 0.034 & ILMN_1765091 & $-0.048(-0.074,-0.022)$ & $3.71 \times 10^{-4}$ & 0.002 \\
\hline LGALS2 & 22 & cg07855639 & $0.081(0.043,0.120)$ & $3.28 \times 10^{-5}$ & 0.034 & ILMN_1687306 & $-0.147(-0.240,-0.053)$ & 0.002 & 0.005 \\
\hline ANKRD11 & 16 & cg07598385 & $0.108(0.056,0.160)$ & $4.97 \times 10^{-5}$ & 0.034 & ILMN_2108709 & $-0.075(-0.142,-0.008)$ & 0.028 & 0.046 \\
\hline$B A Z 2 B$ & 2 & cg17360854 & $0.081(0.042,0.120)$ & $5.08 \times 10^{-5}$ & 0.034 & ILMN_1720850 & $-0.016(-0.060,0.027)$ & 0.463 & 0.578 \\
\hline PPIE & 1 & cg23599683 & $-0.057(-0.085,-0.029)$ & $7.17 \times 10^{-5}$ & 0.039 & ILMN_1680341 & $0.004(-0.020,0.028)$ & 0.728 & 0.728 \\
\hline
\end{tabular}

$\mathrm{PM}_{2.5}$, fine particulate matter (per $2.5 \mu \mathrm{g} / \mathrm{m}^{3}$ ); chr chromosome, $\mathrm{Cl}$ confidence interval

${ }^{a}$ Gene corresponding to Illumina transcript associated with $\mathrm{CpG}$ methylation 
Table 3 Association between global DNA methylation (Alu and LINE-1) and one-year average $\mathrm{PM}_{2.5}$ (per $2.5 \mu \mathrm{g} / \mathrm{m}^{3}$ ) and $\mathrm{NO}_{\mathrm{X}}$ (per $30 \mathrm{ppb}$ )

\begin{tabular}{llllll}
\hline & $P_{2} M_{2.5}$ & & & $N O_{x}$ & \\
\cline { 2 - 3 } \cline { 5 - 6 } & $\beta\left(95 \%()^{\mathrm{a}}\right.$ & $P$-value & & $\beta(95 \% \mathrm{Cl})^{\mathrm{a}}$ & $P$-value \\
\hline Alu & $-0.003(-0.006,0.001)$ & 0.155 & & $0.001(-0.006,0.008)$ & 0.719 \\
LINE-1 & $-0.003(-0.007,0.001)$ & 0.177 & & $-0.0004(-0.009,0.008)$ & 0.927 \\
\hline
\end{tabular}

$\mathrm{PM}_{2.5}$, fine particulate matter; NOX oxides of nitrogen, $\mathrm{Cl}$ confidence interval, LINE-1 long interspersed element 1

a Models adjusted for age, race/ethnicity, sex, study site, income, education, neighborhood socioeconomic status factor score, cigarette smoking, secondhand smoke, body mass index, physical activity, methyl nutrient intake (folate, vitamin B12, vitamin B6, methionine, zinc), residual cell contamination by non-monocytes, recent infection, and methylation chip position. Methylation values were adjusted for methylation chip prior to regression analysis

LGALS2 encodes the protein galectin-2, which is part of the galectin family [52]. Prior studies of LGALS2 function and disease associations have been inconsistent and sometimes conflicting. Higher galectin-2 levels in monocytes and macrophages are linked to low arteriogenic response in coronary artery disease patients [53] and inflammation [54]. A case-control study in Japan first reported that the $3279 \mathrm{C}>\mathrm{T}(\mathrm{rs} 7291467)$ polymorphism, which reduces galectin expression, was negatively associated with risk of myocardial infarction [55]. This single nucleotide polymorphism is located over $380 \mathrm{~kb}$ away from the LGALS2-eMS cg07855639. However, subsequent studies in other Asian and European populations provided mixed results [56-61]. Studies even found the TT genotype, which leads to lower levels of galectin-2, to be associated with more severe coronary stenosis [62] and higher levels of C-reactive protein [60]. Moreover, addition of galectin- 2 to activated $\mathrm{T}$ cells downregulates production of the pro-inflammatory cytokines interferon- $\gamma$ and tumor necrosis factor- $\alpha$, while increasing secretion of interleukin-5 and the antiinflammatory cytokine interleukin-10 [63].

Thus while prior studies suggest that galectin-2 may play a role in cardiovascular disease, potentially by modulating both pro-inflammatory and anti-inflammatory cytokines, the mechanism and direction of association remain to be determined. In our study, $\mathrm{PM}_{2.5}$ exposure was positively associated with methylation of the LGALS2-eMS $\operatorname{cg} 07855639$ and negatively associated with LGALS2 mRNA expression in monocytes. While these results suggest that air pollution may potentially affect inflammation, it is difficult to interpret our results in the context of past studies given the inconsistency in galectin-2 disease associations.

ANKRD11 regulates chromatin modification and has been found to be associated with autism [64] and KBG syndrome (rare disorder marked by dental, neurobehavioral, craniofacial and skeletal anomalies) [65]. In our cohort, $\mathrm{PM}_{2.5}$ was positively associated with ANKRD11 methylation and negatively associated with ANKRD11
mRNA expression. Although air pollution is a risk factor for cardiovascular disease, air pollution has also been linked to other complex diseases such as autism, where the common mechanism might be inflammation [66].

$B A Z 2 B$ and PPIE methylation, but not mRNA expression, were significantly associated with $\mathrm{PM}_{2.5}$ exposure. $B A Z 2 B$ encodes a bromodomain containing chromatin remodeling protein that epigenetically regulates transcription. Although the function of $B A Z 2 B$ remains unclear, single nucleotide polymorphisms in $B A Z 2 B$ were associated with sudden cardiac death [67]. PPIE belongs to the family of PPIases with proline isomerase activity that stimulates folding and conformational changes in proteins and may be linked to leukemia [68], colorectal cancer [69], and body mass index [70]. Although it is uncertain how these genes may be related to air pollution-related disease, this is the first study to report the novel associations between air pollution and $B A Z 2 B$ and PPIE.

While many prior studies focused on the association between air pollution exposure and global DNA methylation, there is also evidence that air pollution is associated with DNA methylation of specific genes. Previous studies identified significant associations between air pollution exposure and differences in DNA methylation of several genes including iNOS [71, 72], tissue factor, intercellular adhesion molecule 1, toll-like receptor 2, interferon- $\gamma$, and interleukin-6 [23]. In addition, an epigenome-wide study of whole blood using the $450 \mathrm{k}$ array identified $12 \mathrm{CpG}$ sites associated with short- and mid-term $\mathrm{PM}_{2.5}$ exposures at genome-wide significance [73]. Of these genes and CpG sites with methylation previously reported to be associated with air pollution, we only analyzed methylation of intercellular adhesion molecule 1 in this study, and it was not associated with long-term $\mathrm{PM}_{2.5}$ or $\mathrm{NO}_{\mathrm{X}}$ exposure. The other genes were not represented among our list of candidate methylation sites, so we did not analyze the association between their DNA methylation and air pollution exposure.

We were unable to replicate prior observational studies that found significant associations between air pollution exposure and global DNA methylation using Alu and LINE-1 methylation as surrogates [22, 26, 74]. Short-term controlled human experiments (blood collected 1-30 h post-exposure) showed that exposure to air pollutants changed DNA methylation levels of Alu and LINE-1 elements [75, 76]. However, other studies did not find an association between air pollution and LINE-1 and/or Alu DNA methylation [22, 71, 74].

Differences in assay method may partially explain our null associations with global DNA methylation. We assessed global DNA methylation using probes on the Illumina 450k array that map to Alu and LINE-1 repetitive elements, unlike most previous studies that used 
pyrosequencing. We also adjusted for a wider array of potential confounders not available in prior studies. Furthermore, our study examined DNA methylation in purified monocytes whereas previous studies used a mixture of blood cells. Monocytes constitute about 5-10\% of peripheral blood leukocytes [77], highlighting the possibility that the association between air pollution and global DNA hypomethylation may be specific to other leukocytes. Moreover, our study population differs from those of prior studies. Our study included men and women age 65 and over who reside in six U.S. regions. Prior studies included a variety of study populations including an elderly cohort of men from the Boston area (mean age 73), [22, 25] healthy male workers from an electric steel furnace plant in Italy (mean age 44), [26] and a predominantly male group of workers from the $\mathrm{Ma} \mathrm{Ta}$ Phut industrial estate in Thailand (mean age 31) [74].

We considered the possibility that the difference in air pollution exposure time windows may explain our non-significant findings. Previous studies found significant associations for short- and intermediate-term air pollution exposure, rather than long-term exposures that are the primary focus of the MESA Air project. A study of air pollution and percent 5methyl-2'-deoxycytidine methylation found the strongest associations above 7 days, with most of the effects observed for the 5- to 30-day moving average exposures [78]. However, in our study, the associations between 2 -week average air pollutant concentrations and global DNA methylation were not significant in sensitivity analyses.

In our study, we only identified CpGs significantly associated with $\mathrm{PM}_{2.5}$ but not $\mathrm{NO}_{\mathrm{X}}$ (at FDR of 0.05). Sources of ambient $\mathrm{PM}_{2.5}$ include energy generation, combustion of fuel, agricultural and industrial processes, and road and wind-blown dust [79]. While motor vehicle emissions contribute to ambient $\mathrm{PM}_{2.5}$, these emissions are one of the main anthropogenic sources of ambient $\mathrm{NO}_{\mathrm{X}}$. Thus, differences in sources and composition of these two pollutants may partially explain why observed associations of $\mathrm{PM}_{2.5}$ with methylation were not observed for $\mathrm{NO}_{\mathrm{X}}$.

There are limitations to our study. Our analysis was cross-sectional, and we were unable to make inferences about the effect of air pollution on changes in DNA methylation. In addition, our study was comprised of individuals in the United States, which has relatively low air pollution concentrations compared to many parts of the world. Higher concentrations of air pollutants may trigger alternate disease mechanisms not captured in this analysis. Additionally, there may be effect modifiers of the air pollution-DNA methylation association not investigated in this study. However, in our sensitivity analyses we did not find evidence of effect modification by sex or race/ethnicity. Finally, there may be residual confounding by factors not included in the analysis.

Our study is distinct in several ways. Our focus on purified monocytes greatly enhances the interpretability of our results and our ability to tease out monocytespecific differentially methylated signals that are important in atherosclerosis. Furthermore, the populationbased sampling, younger age, and multiracial nature of the MESA cohort allows for greater generalizability of study results. The coupling of DNA methylation and gene expression data aids the detection of differentially methylated sites that may be functionally relevant. Finally, the state-of-art air pollution assessment in MESA Air provides individual-level exposures that capture fine-scale spatial variability in air pollution to greatly reduce measurement error.

\section{Conclusions}

Long-term ambient air pollution exposure was associated with site-specific DNA methylation, but not global DNA methylation, in purified blood monocytes obtained from a multi-ethnic adult population. We identified genes that may be functionally relevant to mediating air pollution health effects by focusing on expressionassociated methylation sites. We report novel associations between $\mathrm{PM}_{2.5}$ exposure and DNA methylation and expression of ANKHD1, LGALS2, and ANKRD11. Future research in blood monocytes could address whether air pollution-associated diseases-such as atherosclerosis-may be mediated in part by DNA methylation epigenetic reprogramming.

\section{Additional file}

Additional file 1: Supplemental Material. (DOCX $39 \mathrm{~kb})$

\section{Abbreviations}

450k: HumanMethylation450 BeadChip; ANKHD1: Ankyrin repeat and KH domain containing 1; ANKRD11: Ankyrin repeat domain 11; BAZ2B: Bromodomain adjacent to zinc finger domain, 2B; Cl: Confidence interval; $\mathrm{CpG}$ site: Cytosineguanine dinucleotide site; CVD: Cardiovascular disease; eMS: Expressionassociated methylation sites; ENCODE: Encyclopedia of DNA Elements; FDR: False discovery rate; IQR: Interquartile range; LGALS2: Lectin, galactosidebinding, soluble, 2; LINE: Long interspersed nuclear elements; MESA: Multi-Ethnic Study of Atherosclerosis; $\mathrm{NO}_{\mathrm{x}}$ : Oxides of nitrogen; $\mathrm{PM}_{2.5}$ : Fine particulate matter; PPIE: Peptidylprolyl isomerase $\mathrm{E}$

\section{Acknowledgements}

The authors would like to acknowledge the MESA Air Data Team, especially Logan Piepmeier, for their assistance in generating air pollution predictions and maps.

\section{Funding}

This work was supported by National Institute of Environmental Health Sciences (NIEHS, 1 F31 ES025475-01, P30 ES007033, P50 ES015915-01). This research was also supported by contracts T32 HL007902, N01-HC-95159, N01-HC-95160, N01-HC-95161, N01-HC-95162, N01-HC-95163, N01-HC-95164, N01-HC-95165, N01-HC-95166, N01-HC-95167, N01-HC-95168, N01-HC-95169, and 2R01 HL071759 from the National Heart, Lung, and Blood Institute and 
by grants UL1-TR-000040 and UL1-TR-001079 from NCRR. The authors thank the other investigators, the staff, and the participants of the MESA study for their valuable contributions. A full list of participating MESA investigators and institutions can be found at http://www.mesa-nhlbi.org. This publication was developed under a STAR research assistance agreement, No. RD831697 (MESA Air), awarded by the U.S Environmental protection Agency. It has not been formally reviewed by the EPA. The views expressed in this document are solely those of the authors and the EPA does not endorse any products or commercial services mentioned in this publication. The MESA Epigenomics \& Transcriptomics Study was funded by NHLBI grant 1R01HL101250-01 to Wake Forest University Health Sciences. The contents are solely the responsibility of the authors and do not necessarily represent the official views of the NHLBI, USEPA, or NIEHS.

\section{Availability of data and materials}

The datasets supporting the conclusions of this article are available in the NCBI Gene Expression Omnibus repository, GEO Series accession number GSE56046 in http://www.ncbi.nlm.nih.gov/geo/query/acc.cgi?acc=GSE56046.

\section{Authors' contributions}

GCC contributed to the statistical design, conducted statistical analyses, and drafted the manuscript. YL collected DNA methylation and gene expression data and participated in manuscript writing. JM contributed to statistical design and participated in manuscript writing. RGB participated in manuscript writing. KMD participated in manuscript writing. MDH participated in manuscript writing. MDH participated in manuscript writing. Lifang Hou participated in manuscript writing. CEM participated in manuscript writing. LMR participated in statistical analysis and manuscript writing. DSS participated in manuscript writing. JDK collected air pollution data, participated in statistical design, and participated in manuscript writing. All authors read and approved the final manuscript.

\section{Competing interests}

The authors declare that they have no competing interests.

\section{Consent for publication}

Not applicable.

\section{Ethics approval and consent to participate}

The study protocol was approved by the Institutional Review Boards at Johns Hopkins Medical Institutions, University of Minnesota, Columbia University Medical Center, Wake Forest University Health Sciences, and University of Washington. All participants signed informed consent.

\section{Author details}

${ }^{1}$ Department of Epidemiology, School of Public Health, University of Washington, 1959 NE Pacific St, Box 357236, Seattle, WA 98195, USA. ${ }^{2}$ Department of Epidemiology \& Prevention, Division of Public Health Sciences, Wake Forest School of Medicine, Winston-Salem, NC, USA. ${ }^{3}$ Department of Environmental and Occupational Health Sciences, School of Public Health, University of Washington, Seattle, WA, USA. ${ }^{4}$ Division of General Medicine, Mailman School of Public Health, Columbia University, New York, NY, USA. ${ }^{5}$ Division of Pulmonary, Allergy \& Critical Care, Columbia University Medical Center, New York, NY, USA. ${ }^{6}$ Department of Preventive Medicine, Division of Cancer Epidemiology and Prevention, Feinberg School of Medicine, Northwestern University, Chicago, IL, USA. ${ }^{7}$ Section on Molecular Medicine, Wake Forest School of Medicine, Winston-Salem, NC, USA. ${ }^{8}$ New York Academy of Medicine, New York, NY, USA.

\section{Received: 27 June 2016 Accepted: 24 November 2016}

\section{Published online: 01 December 2016}

\section{References}

1. Lim SS, Vos T, Flaxman AD, Danaei G, Shibuya K, Adair-Rohani H, et al. A comparative risk assessment of burden of disease and injury attributable to 67 risk factors and risk factor clusters in 21 regions, 1990-2010: a systematic analysis for the Global Burden of Disease Study 2010. Lancet. 2013;380:2224-60.

2. Olmo NRS, do Nascimento Saldiva PH, Braga ALF, Lin CA, de Paula Santos U, Pereira LAA. A review of low-level air pollution and adverse effects on human health: implications for epidemiological studies and public policy. Clinics. 2011;66:681-90.

3. Dockery DW, Pope CA, Xu X, Spengler JD, Ware JH, Fay ME, et al. An association between air pollution and mortality in six U.S. cities. N Engl J Med. 1993;329:1753-9.

4. Laden F, Schwartz J, Speizer FE, Dockery DW. Reduction in fine particulate Air pollution and mortality. Am J Respir Crit Care Med. 2006;173:667-72.

5. Lepeule J, Laden F, Dockery D, Schwartz J. Chronic exposure to fine particles and mortality: an extended follow-up of the Harvard Six cities study from 1974 to 2009. Environ Health Perspect. 2012;120:965-70.

6. Pope CA, Thun MJ, Namboodiri MM, Dockery DW, Evans JS, Speizer FE, et al Particulate Air pollution as a predictor of mortality in a prospective study of U.S. Adults. Am J Respir Crit Care Med. 1995;151:669-74.

7. Pope CA, Burnett RT, Thun MJ, Calle EE, Krewski D, Ito K, et al. Lung cancer, cardiopulmonary mortality, and long-term exposure to fine particulate air pollution. JAMA. 2002;287:1132-41.

8. Jerrett M, Burnett RT, Ma R, Pope CA, Krewski D, Newbold KB, et al. Spatial analysis of air pollution and mortality in Los Angeles. Epidemiol Camb Mass. 2005;16:727-36.

9. Brook RD, Rajagopalan S, Pope CA, Brook JR, Bhatnagar A, Diez-Roux AV, et al. Particulate matter air pollution and cardiovascular disease: An update to the scientific statement from the American Heart Association. Circulation. 2010;121:2331-78

10. Miller KA, Siscovick DS, Sheppard L, Shepherd K, Sullivan JH, Anderson GL, et al. Long-term exposure to air pollution and incidence of cardiovascular events in women. N Engl J Med. 2007;356:447-58.

11. Dominici F, Peng RD, Bell ML, Pham L, McDermott A, Zeger SL, et al. Fine particulate air pollution and hospital admission for cardiovascular and respiratory diseases. JAMA. 2006;295:1127-34.

12. Kaufman JD, Adar SD, Barr RG, Budoff M, Burke GL, Curl CL, et al. Association between air pollution and coronary artery calcification within six metropolitan areas in the USA (the Multi-Ethnic Study of Atherosclerosis and Air Pollution): a longitudinal cohort study. Lancet. 2016:388:696-704

13. Cesaroni G, Forastiere F, Stafoggia M, Andersen ZJ, Badaloni C, Beelen R, et al. Long term exposure to ambient air pollution and incidence of acute coronary events: prospective cohort study and meta-analysis in 11 European cohorts from the ESCAPE Project. BMJ. 2014;348:f7412.

14. Zhang L, Chen X, Xue X, Sun M, Han B, Li C, et al. Long-term exposure to high particulate matter pollution and cardiovascular mortality: A 12-year cohort study in four cities in northern China. Environ Int. 2014;62:41-7.

15. Zhang P, Dong G, Sun B, Zhang L, Chen X, Ma N, et al. Long-term exposure to ambient Air pollution and mortality Due to cardiovascular disease and cerebrovascular disease in Shenyang. China PLOS ONE. 2011;6:e20827.

16. Hoek G, Krishnan RM, Beelen R, Peters A, Ostro B, Brunekreef B, et al. Longterm air pollution exposure and cardio- respiratory mortality: a review. Environ Health. 2013:12:43.

17. Hou L, Zhang X, Wang D, Baccarelli A. Environmental chemical exposures and human epigenetics. Int J Epidemiol. 2012;41:79-105.

18. Smith ZD, Meissner A. DNA methylation: roles in mammalian development. Nat Rev Genet. 2013:14:204-20.

19. Turunen MP, Aavik E, Ylä-Herttuala S. Epigenetics and atherosclerosis. Biochim Biophys Acta BBA-Gen Subj. 2009;1790:886-91.

20. Baccarelli A, Wright R, Bollati V, Litonjua A, Zanobetti A, Tarantini L, et al. Ischemic heart disease and stroke in relation to blood DNA methylation. Epidemiology. 2010;21:819.

21. Kim M, Long TI, Arakawa K, Wang R, Mimi CY, Laird PW. DNA methylation as a biomarker for cardiovascular disease risk. PLoS One. 2010;5:e9692.

22. Baccarelli A, Wright RO, Bollati V, Tarantini L, Litonjua AA, Suh HH, et al. Rapid DNA Methylation Changes after Exposure to Traffic Particles. Am J Respir Crit Care Med. 2009;179:572-8.

23. Bind M-A, Lepeule J, Zanobetti A, Gasparrini A, Baccarelli AA, Coull BA, et al. Air pollution and gene-specific methylation in the Normative Aging Study. Epigenetics. 2014;9:448-58.

24. Bollati V, Baccarelli A, Hou L, Bonzini M, Fustinoni S, Cavallo D, et al. Changes in DNA methylation patterns in subjects exposed to low-dose benzene. Cancer Res. 2007;67:876-80.

25. Madrigano J, Baccarelli A, Mittleman MA, Wright RO, Sparrow D, Vokonas PS, et al. Prolonged exposure to particulate pollution, genes associated with glutathione pathways, and DNA methylation in a cohort of older men. Environ Health Perspect. 2011;119:977-82. 
26. Tarantini $L$, Bonzini $M$, Apostoli P, Pegoraro V, Bollati V, Marinelli B, et al. Effects of particulate matter on genomic DNA methylation content and iNOS promoter methylation. Environ Health Perspect. 2009;117:217-22.

27. Woollard KJ, Geissmann F. Monocytes in atherosclerosis: subsets and functions. Nat Rev Cardiol. 2010;7:77-86.

28. Bild DE, Bluemke DA, Burke GL, Detrano R, Roux AVD, Folsom AR, et al. Multi-ethnic study of atherosclerosis: objectives and design. Am J Epidemiol. 2002;156:871-81.

29. Kaufman JD, Adar SD, Allen RW, Barr RG, Budoff MJ, Burke GL, et al. Prospective study of particulate Air pollution exposures, subclinical atherosclerosis, and clinical cardiovascular disease: : the Multi-Ethnic Study of Atherosclerosis and Air pollution (MESA Air). Am J Epidemiol. 2012;176:825-37.

30. Liu Y, Ding J, Reynolds LM, Lohman K, Register TC, Fuente ADL, et al. Methylomics of gene expression in human monocytes. Hum Mol Genet. 2013;22:5065-74.

31. Cohen MA, Adar SD, Allen RW, Avol E, Curl CL, Gould T, et al. Approach to estimating participant pollutant exposures in the Multi-Ethnic Study of Atherosclerosis and Air pollution (MESA Air). Environ Sci Technol. 2009;43: 4687-93.

32. Keller JP, Olives C, Kim S-Y, Sheppard L, Sampson PD, Szpiro AA, et al. A unified spatiotemporal modeling approach for predicting concentrations of multiple Air pollutants in the multi-ethnic study of atherosclerosis and air pollution. Environ Health Perspect. 2015;123:301-9.

33. Matte TD, Ross Z, Kheirbek I, Eisl H, Johnson S, Gorczynski JE, et al. Monitoring intraurban spatial patterns of multiple combustion air pollutants in New York City: design and implementation. J Expo Sci Environ Epidemiol. 2013;23:223-31.

34. Du P, Zhang X, Huang CC, Jafari N, Kibbe WA, Hou L, et al. Comparison of Beta-value and M-value methods for quantifying methylation levels by microarray analysis. BMC Bioinformatics. 2010;11:587. -2105-11-587.

35. Gentleman RC, Carey VJ, Bates DM, Bolstad B, Dettling M, Dudoit S, et al. Bioconductor: open software development for computational biology and bioinformatics. Genome Biol. 2004;5:R80.

36. R Core Team. R: A language and environment for statistical computing [Internet]. Vienna: R Foundation for Statistical Computing; 2015. Available from: https://www.R-project.org/.

37. Smit AF, Hubley R, Green P. RepeatMasker Open-30. 1996

38. Ritchie ME, Phipson B, Wu D, Hu Y, Law CW, Shi W, Smyth GK. limma powers differential expression analyses for RNA-sequencing and microarray studies. Nucleic Acids Res. 2015;43(7):e47.

39. Benjamini $Y$, Hochberg Y. Controlling the false discovery rate: a practical and powerful approach to multiple testing. J R Stat Soc B Methodol. 1995; 57:289-300.

40. StataCorp. Stata Statistical Software: Release 13. College Station: StataCorp LP; 2013.

41. Ernst J, Kellis M. ChromHMM: automating chromatin-state discovery and characterization. Nat Methods. 2012;9:215-6.

42. Adams D, Altucci L, Antonarakis SE, Ballesteros J, Beck S, Bird A, et al. BLUEPRINT to decode the epigenetic signature written in blood. Nat Biotechnol. 2012;30:224-6.

43. Saeed S, Quintin J, Kerstens HHD, Rao NA, Aghajanirefah A, Matarese F, et al. Epigenetic programming during monocyte to macrophage differentiation and trained innate immunity. Science. 2014;345:1251086.

44. Rosenbloom KR, Sloan CA, Malladi VS, Dreszer TR, Learned K, Kirkup VM, et al. ENCODE data in the UCSC Genome Browser: year 5 update. Nucleic Acids Res. 2013:41:D56-63.

45. Karolchik D, Barber GP, Casper J, Clawson H, Cline MS, Diekhans M, et al. The UCSC Genome Browser database: 2014 update. Nucleic Acids Res. 2014;42:D764-70.

46. Dhyani A, Duarte ASS, Machado-Neto JA, Favaro P, Ortega MM, Olalla Saad ST. ANKHD1 regulates cell cycle progression and proliferation in multiple myeloma cells. FEBS Lett. 2012;586:4311-8.

47. Machado-Neto JA, Lazarini M, Favaro P, Franchi Jr GC, Nowill AE, Saad STO et al. ANKHD1, a novel component of the Hippo signaling pathway, promotes YAP1 activation and cell cycle progression in prostate cancer cells. Exp Cell Res. 2014;324:137-45.

48. Machado-Neto JA, Lazarini M, Favaro P, de Melo CP, Scopim-Ribeiro R, Franchi Junior GC, et al. ANKHD1 silencing inhibits Stathmin 1 activity, cell proliferation and migration of leukemia cells. Biochim Biophys Acta BBA Mol Cell Res. 1853;2015:583-93.
49. Traina F, Favaro PMB, de Souza Medina S, da Silva Santos Duarte A, Brochado Winnischofer SM, Costa FF, et al. ANKHD1, ankyrin repeat and KH domain containing 1, is overexpressed in acute leukemias and is associated with SHP2 in K562 cells. Biochim. Biophys. Acta BBA - Mol Basis Dis. 2006; 1762:828-34.

50. Miles MC, Janket ML, Wheeler EDA, Chattopadhyay A, Majumder B, DeRicco $J$, et al. Molecular and functional characterization of a novel splice variant of ANKHD1 that lacks the $\mathrm{KH}$ domain and its role in cell survival and apoptosisc. FEBS J. 2005;272:4091-102.

51. Mosavi LK, Cammett TJ, Desrosiers DC, Peng Z. The ankyrin repeat as molecular architecture for protein recognition. Protein Sci Publ Protein Soc. 2004;13:1435-48.

52. Cummings RD, Liu F-T. Galectins. In: Varki A, Cummings RD, Esko JD, Freeze HH, Stanley P, Bertozzi CR, et al., editors. Essent. Glycobiol. 2nd ed. Cold Spring Harbor: Cold Spring Harbor Laboratory Press; 2009. [cited 2015 Nov 6]. Available from: http://www.ncbi.nlm.nih.gov/books/NBK1944/.

53. van der Laan AM, Schirmer SH, de Vries MR, Koning JJ, Volger OL, Fledderus JO, et al. Galectin-2 expression is dependent on the rs7291467 polymorphism and acts as an inhibitor of arteriogenesis. Eur Heart J. 2012;33:1076-84.

54. Yıldırım C, Vogel DYS, Hollander MR, Baggen JM, Fontijn RD, Nieuwenhuis S, et al. Galectin-2 Induces a Proinflammatory, Anti-Arteriogenic Phenotype in Monocytes and Macrophages. PLoS One. 2015;10(4):e0124347.

55. Ozaki K, Inoue K, Sato H, lida A, Ohnishi Y, Sekine A, et al. Functional variation in LGALS2 confers risk of myocardial infarction and regulates lymphotoxin-a secretion in vitro. Nature. 2004;429:72-5.

56. Kimura A, Takahashi M, Choi BY, Bae SW, Hohta S, Sasaoka T, et al. Lack of association between LTA and LGALS2 polymorphisms and myocardial infarction in Japanese and Korean populations. Tissue Antigens. 2007;69:265-9.

57. Sedlacek K, Neureuther K, Mueller JC, Stark K, Fischer M, Baessler A, et al. Lymphotoxin-alpha and galectin-2 SNPs are not associated with myocardial infarction in two different German populations. J Mol Med Berl Ger. 2007;85: 997-1004.

58. Koch W, Hoppmann P, Michou E, Jung V, Pfeufer A, Mueller JC, et al. Association of variants in the BAT1-NFKBIL1-LTA genomic region with protection against myocardial infarction in Europeans. Hum Mol Genet. 2007;16:1821-7.

59. Mangino M, Braund P, Singh R, Steeds R, Thompson JR, Channer K, et al. LGALS2 functional variant rs7291467 is not associated with susceptibility to myocardial infarction in Caucasians. Atherosclerosis. 2007;194:112-5.

60. Asselbergs FW, Pai JK, Rexrode KM, Hunter DJ, Rimm EB. Effects of lymphotoxin-a gene and galectin-2 gene polymorphisms on inflammatory biomarkers, cellular adhesion molecules and risk of coronary heart disease. Clin Sci. 2007;112:291-8.

61. Lian J, Lian J, Fang P, Fang P, Dai D, Dai D, et al. Association between LGALS2 3279C>T and coronary artery disease: A case-control study and a meta-analysis. Biomed Rep. 2014. doi:10.3892/br.2014.325.

62. Ikeda S, Tanaka N, Arai T, Chida K, Muramatsu M, Sawabe M. Polymorphisms of LTA, LGALS2, and PSMA6 genes and coronary atherosclerosis: A pathological study of 1503 consecutive autopsy cases. Atherosclerosis. 2012;221:458-60.

63. Sturm A, Lensch M, André S, Kaltner H, Wiedenmann B, Rosewicz S, et al. Human Galectin-2: Novel Inducer of T Cell Apoptosis with Distinct Profile of Caspase Activation. J Immunol. 2004;173:3825-37.

64. Gallagher D, Voronova A, Zander MA, Cancino Gl, Bramall A, Krause MP, et al. Ankrd11 Is a Chromatin Regulator Involved in Autism that Is Essential for Neural Development. Dev Cell. 2015;32:31-42.

65. Ockeloen CW, Willemsen MH, de Munnik S, van Bon BW, de Leeuw N, Verrips $A$, et al. Further delineation of the KBG syndrome phenotype caused by ANKRD11 aberrations. Eur J Hum Genet. 2015;23:1176-85.

66. Allen JL, Oberdorster G, Morris-Schaffer K, Wong C, Klocke C, Sobolewski M, et al. Developmental neurotoxicity of inhaled ambient ultrafine particle air pollution: Parallels with neuropathological and behavioral features of autism and other neurodevelopmental disorders. NeuroToxicology [Internet]. [cited 2016 Jan 11]; Available from: http://www.sciencedirect.com/science/article/ pii/S0161813X15300486. Accessed 11 Jan 2016.

67. Arking DE, Junttila MJ, Goyette P, Huertas-Vazquez A, Eijgelsheim M, Blom MT, et al. Identification of a Sudden Cardiac Death Susceptibility Locus at 2q24.2 through Genome-Wide Association in European Ancestry Individuals. PLoS Genet. 2011;7(6):e1002158.

68. Wang Z, Song J, Milne TA, Wang GG, Li H, Allis CD, et al. Pro Isomerization in MLL1 PHD3-Bromo Cassette Connects H3K4me Readout to CyP33 and HDAC-Mediated Repression. Cell. 2010;141:1183-94. 
69. Morris AR, Bos A, Diosdado B, Rooijers K, Elkon R, Bolijn AS, et al. Alternative Cleavage and Polyadenylation during Colorectal Cancer Development. Clin Cancer Res. 2012;18:5256-66.

70. Naukkarinen J, Surakka I, Pietiläinen KH, Rissanen A, Salomaa V, Ripatti S, et al. Use of Genome-Wide Expression Data to Mine the "Gray Zone" of GWA Studies Leads to Novel Candidate Obesity Genes. PLoS Genet. 2010;6(6): e1000976.

71. Kile ML, Fang S, Baccarelli AA, Tarantini L, Cavallari J, Christiani DC. A panel study of occupational exposure to fine particulate matter and changes in DNA methylation over a single workday and years worked in boilermaker welders. Environ Health. 2013;12:47.

72. Madrigano J, Baccarelli A, Mittleman MA, Sparrow D, Spiro A, Vokonas PS, et al. Air Pollution and DNA Methylation: Interaction by Psychological Factors in the VA Normative Aging Study. Am J Epidemiol. 2012;176:224-32.

73. Panni T, Mehta AJ, Schwartz JD, Baccarelli AA, Just AC, Wolf K, et al. A Genome-Wide Analysis of DNA Methylation and Fine Particulate Matter Air Pollution in Three Study Populations: KORA F3, KORA F4, and the Normative Aging Study. Environ Health Perspect. 2016. doi:10.1289/ehp.1509966.

74. Peluso M, Bollati V, Munnia A, Srivatanakul P, Jedpiyawongse A, Sangrajrang $S$, et al. DNA methylation differences in exposed workers and nearby residents of the Ma Ta Phut industrial estate, Rayong, Thailand. Int J Epidemiol. 2012:41:1753-60.

75. Bellavia A, Urch B, Speck M, Brook RD, Scott JA, Albetti B, et al. DNA Hypomethylation, Ambient Particulate Matter, and Increased Blood Pressure: Findings From Controlled Human Exposure Experiments. J Am Heart Assoc Cardiovasc Cerebrovasc Dis. 2013;2(3):e000212.

76. Jiang R, Jones MJ, Sava F, Kobor MS, Carlsten C. Short-term diesel exhaust inhalation in a controlled human crossover study is associated with changes in DNA methylation of circulating mononuclear cells in asthmatics. Part Fibre Toxicol. 2014;11:71.

77. Gordon S, Taylor PR. Monocyte and macrophage heterogeneity. Nat Rev Immunol. 2005;5:953-64.

78. De Prins S, Koppen G, Jacobs G, Dons E, Van de Mieroop E, Nelen V, et al. Influence of ambient air pollution on global DNA methylation in healthy adults: A seasonal follow-up. Environ Int. 2013:59:418-24.

79. Brook RD, Franklin B, Cascio W, Hong Y, Howard G, Lipsett M, et al. Air pollution and cardiovascular disease: a statement for healthcare professionals from the expert panel on population and prevention science of the American Heart Association. Circulation. 2004;109:2655-71.

\section{Submit your next manuscript to BioMed Central and we will help you at every step:}

- We accept pre-submission inquiries

- Our selector tool helps you to find the most relevant journal

- We provide round the clock customer support

- Convenient online submission

- Thorough peer review

- Inclusion in PubMed and all major indexing services

- Maximum visibility for your research

Submit your manuscript at www.biomedcentral.com/submit

) Biomed Central 